\title{
Levels of job dissatisfaction and work- related stressors experienced by medical doctors in Greek hospitals
}

\author{
Alexander-Stamatios Antoniou ${ }^{1 *}$, Cary L. Cooper ${ }^{2}$ and Marilyn J. Davidson ${ }^{2}$
}

\begin{abstract}
Background: Although a considerable number of studies have been conducted with regard to work well-being of medical personnel, few of these have focused on smaller countries with a cultural setting such as Greece. In specific, much attention has been given to the mental health of medical doctors who appear to be at high risk and prone to a number of job stressors. Many of these factors can significantly reduce their general ability to respond effectively to their demanding duties. The present study investigates the extent to which specific occupational stressors may predict various aspects of job satisfaction amongst 514 Greek hospital doctors.

Methods: The main sample consisted of 277 male and 237 female doctors covering the spectrum of the typical hospital hierarchy, who completed the author Hospital Doctors Stress Questionnaire, the Occupational Stress Indicator (OSI) and a Job Satisfaction scale.

Results: Analyses of the data demonstrated that, overall, hospital doctors presented low levels of job satisfaction in relation to salary, working hours, opportunities for promotion and general working conditions. The highest levels of satisfaction were indicated with regard to relationships with colleagues and superiors, responsibilities, and appreciation for their work.

Conclusions: The results of this study identify that certain occupational stress factors influence the overall job satisfaction of Greek hospital doctors. Finally, as regards to demographic variables as potential predictors of job satisfaction, presence of physical symptoms, specialism and age were significantly associated to the overall job satisfaction.
\end{abstract}

Keywords: Job dissatisfaction, Occupational stressors, Hospital doctors, Working conditions, High-risk jobs/ populations, Personality

\section{Background}

Although a wealth of studies have been conducted with regard to stress and occupational stressors in medical personnel, few of these have focused on smaller countries with a specific cultural setting such as Greece. The current study therefore attempts to fill this knowledge gap, by investigating key occupational stressors amongst doctors employed within the Greek National Health System, and the extent to which these may act as predictors of job satisfaction.

* Correspondence: asantoni@hol.gr

${ }^{1}$ National and Kapodistrian, University of Athens, Athens, Greece

Full list of author information is available at the end of the article
For some time, considerable attention has been given to the psychological health of doctors (e.g., $[9,41,44])$. Earlier research has indicated that doctors are considered to be at high risk and prone to a number of occupational stressors, which can significantly reduce their ability to respond effectively to their duties (e.g., $[8,10])$.

Many studies have demonstrated that increased psychological distress within the medical profession is associated with a number of factors, including heavy workload, interruption of family life, insufficient training, patient complaints, making decisions alone, and keeping up to date with knowledge (e.g., $[10,11,18,45,46])$.

According to a study by King et al. [28], the three most important causes of occupational stress in medical 
doctors include: a) occupational obligations, b) workload and c) family life. In addition, across the 30 sources of stress examined in one of the most recent UK surveys [18] a number of key occupational stressors were identified such as: a) increasing work load b) increased demands from patients c) paper work d) inappropriate demands from patients e) insufficient time to do justice to the job.

A number of stressors are also perceived to be intrinsic to the medical profession such as experience of emotional intense, fear, failure, death (e.g., [5]), their exposure to an increased danger of disease and injury [3] and the fact that doctor's omission, actions and potential mistakes may have a profound impact on the patient's life [2].

There is a wide scope of literature available, reporting on the measurement of stress in hospital doctors (e.g., $[30,38,40])$, and the extent to which occupational stressors affect doctors differently depending on their position within the hierarchy $[4,24]$. Successful coping with occupational stressors in hospital doctors has been identified as relating to seeking advice from family, friends and partners [33]. Consulting professional help has also been shown to assist doctors in reducing symptoms resulting from professional stress.

A further issue of importance relates to the effects of occupational stressors on the perceived job satisfaction of clinicians. Grol et al. [25, 26] have demonstrated that job satisfaction can affect the quality of health care; it has been shown that doctors' poor clinical performance as evidenced in high prescriptions rates and lack of communication with patients is associated with low job satisfaction in doctors who experience frustration, time pressure and tension. In 1992, after the introduction of new regulations in health care services in Great Britain, research involving 917 General Doctors revealed that they presented lower levels of job dissatisfaction and psychological instability than their counterparts in an earlier study [45]. Researchers also detected a number of parameters that predicted the doctors' job dissatisfaction, such as time pressure and strain related to the patients' needs and expectancies, organisational structure and work environment, future prospects, and managerial duties. In particular, time pressure for patients' consultation has been highlighted as a major stressor affecting job dissatisfaction across many studies (e.g., $[37,43])$. Moreover, doctors with low levels of job satisfaction were more likely to manifest negative attitudes against the health care system as a whole [39].

The above constitutes a brief overview of some of the many research studies into stressors and job satisfaction, which remain somewhat limited within smaller countries such as Greece. Investigations into the extent to which different stressors might predict doctors' dissatisfaction/ satisfaction with their work, in such countries may however have useful implications for neighbouring countries of a similar cultural and economic structure.

The Greek national health system was introduced in 1983, aiming to provide health care for the entire population [34], and to limit the usage of the private sector. Throughout the 1980s, the Greek NHS continued to develop, and a growth in available resources was witnessed. Access to the Greek NHS is free, and is paid for by a number of health insurance schemes, financed mainly by employees and employers.

Despite ongoing intentions of equity and efficiency, since the development of the Greek NHS attempts to reform it have been slow, and various plans have failed as a result of economic, political and social factors [15]. However, public hospitals remain under pressure to improve, particularly in terms of resources and general inefficiencies [6].

Tountas [47] has previously reported the NHS as being in a continuous crisis, caused predominantly by low productivity, administrative problems and insufficient primary care services. However, plans for a major reform of the health system were intended, and almost two decades after its development, initiatives were introduced to modernize the framework [31].

Because of ongoing problems encountered within the Greek NHS, it seems reasonable to assume that specific stressors may lead to job dissatisfaction among Greek hospital doctors, and that identification of these facts may enhance performance and improve psychological and physical health in Greek clinicians. A study by Falagas et al. [19] into the utilization of a hospital based employee health clinic revealed a number of common complaints among Greek hospital staff including abdominal pain, dizziness, respiratory tract infections, and weakness/malaise. However, it was noted that physicians visited the clinic less than other health care professionals, and as such, their symptoms could go unnoticed.

Stress and job satisfaction in Greek doctors may also put them at risk of impaired health behaviour. In an earlier study [36], it was reported that $44 \%$ of internists and $54 \%$ of surgeons smoked more than 20 cigarattes a day, and that $40 \%$ of these reported stress in hospitals as a major cause of not-quitting. This particular study concluded that support from colleagues or families might encourage Greek doctors to stop smoking, and may help them to take a more optimistic view in terms of cancer-prevention practice. A further study by [48], noted that smoking in Greek doctors was related to anxiety, and that stress management programmes could be an effective technique for helping Greek doctors to stop smoking. In order to be investigated the main aims of the present study

Regarding the specific working conditions of Greek medical doctors, the main aims of the study were to examine: 
a) the overall level of job satisfaction/dissatisfaction of the total sample

b) the levels of job satisfaction/dissatisfaction factors

c) the specific stress factors that the doctors experience

d) the prediction of job dissatisfaction/satisfaction levels by certain stress factors and

e) the prediction of job dissatisfaction/satisfaction levels by specific demographic variables.

It was hypothesized, that given the current structure of the healthcare system in Greece, and the low financing that it receives [42], Greek doctors would report job dissatisfaction in specific areas related to these issues, and that certain predicting stressors would be identified. On the contrary, bearing in mind the social structure of Greece, and its traditional societal values, job satisfaction among Greek doctors was expected to emerge with respect to interpersonal relationships.

\section{Methods}

Sample

Prior to the study, permission was sought from the management of the hospitals and the consultants of each hospital clinic. The questionnaires were addressed to hospital doctors working in a number of clinics in large general public hospitals based in the area of Greater Athens. The total response rate was $83.5 \%$ and 514 questionnaires were collected. The difficulty in reaching the sample was mainly due to the time restrictions of the medical doctors working in Greek hospitals. All questionnaires were visually checked for omissions and the usable ones assigned a log number. They were also computer coded and were recorded in a file so that the data were subject to detailed quantitative analysis. The statistical analysis was performed using the Statistical Package for Social Science (SPSS).

The working sample consisted of 514 Greek hospital doctors: 277 (53.9 \%) males and 237 (46.1\%) females. Around 3/4 of the sample was 25-35 years old and the majority was married (see Table 1 ). The participants covered the spectrum of the typical hospital hierarchy (from house officers to consultants), apart from the heads of the departments. Junior Hospital Doctors with 1-6 years work experience comprised $54.7 \%$ of the whole sample. Furthermore, the sample consisted of doctors covering a wide range of medical specialties, with the most represented specialties being pathologists $(53.3 \%)$ and surgeons (30.2 \%).

\section{Measures}

A number of independent and dependent measures were used in this study and these were found to be implicated in previous research into job satisfaction in doctors. Research data was collected through the scales described
Table 1 Demographic Characteristics

\begin{tabular}{|c|c|}
\hline Variables & $\begin{array}{l}\text { Participants } \\
(\mathrm{N}, \%)\end{array}$ \\
\hline \multicolumn{2}{|l|}{ Gender } \\
\hline Males & $277(53.9 \%)$ \\
\hline Females & 237 (46.1\%) \\
\hline \multicolumn{2}{|l|}{ Age } \\
\hline $25-35$ years & 367 (71.4\%) \\
\hline $36-45$ years & $118(23 . \%)$ \\
\hline $46-55$ years & $25(4.9 \%)$ \\
\hline $56-68$ years & $4(0.8)$ \\
\hline \multicolumn{2}{|l|}{ Marital Status } \\
\hline Married & $290(56.4 \%)$ \\
\hline Single & 185 (36 \%) \\
\hline Cohabitants & $7(1.4 \%)$ \\
\hline Divided & $5(1 \%)$ \\
\hline Widowed & $27(5.3 \%)$ \\
\hline \multicolumn{2}{|l|}{ Position } \\
\hline Junior Hospital Doctors & $344(66.9 \%)$ \\
\hline Consultants $\mathrm{A}^{\prime}$ & $42(8.2 \%)$ \\
\hline Consultants B' & $101(19.6 \%)$ \\
\hline Other & $27(5.25 \%)$ \\
\hline \multicolumn{2}{|l|}{ Specialty } \\
\hline Pathologists & $274(53.3 \%)$ \\
\hline Surgeons & $155(30.2 \%)$ \\
\hline Psychiatrists- Neurologists & $23(4.5 \%)$ \\
\hline Laboratory & $62(12.1 \%)$ \\
\hline \multicolumn{2}{|l|}{ Job Experience } \\
\hline $1-3$ years & $114(22.2 \%)$ \\
\hline $4-6$ years & $167(32.5 \%)$ \\
\hline $7-9$ years & $79(15.4 \%)$ \\
\hline 10-15 years & 74 (14.4 \%) \\
\hline $16-25$ years & $27(5.3 \%)$ \\
\hline $26-35$ years & $12(2.3 \%)$ \\
\hline
\end{tabular}

below. These were administered to the participants by researchers in their working environments.

a) Stress Scale (OSI): The "work pressures" scale of the Occupational Stress Indicator (OSI), a selfadministered questionnaire devised by Cooper et al. [12], was used to investigate stress $(\alpha=.86)$. This specific scale consists of six subscales with a total of 61 items, where the respondent has to rate the degree of stress experienced using a six-point Likert-type rating scale. The items are assessed on a scale ranging from 1 ("very definitely is not a 
source" of stress) to 6 ("very definitely is a source" of stress). Thus, the higher the score, the greater the source of stress experienced by the individual. Although the items include various aspects of stress such as relationships and home/work interface, the emphasis is on occupational stress factors. The OSI has been found to be a reliable and valid instrument, and it has been used as a diagnostic tool in a number of studies, especially with samples of doctors $[13,16,23]$.

b) Hospital Doctors Stress Scale/HDSS [1]. This scale was formulated based on transcript analyses of sixty interviews. It consists of items/stressors covering a wide range of various personal and occupational thematic categories. As with the above relevant subscale of the OSI, respondents were required to rate the specific stressors of hospital doctors in one scale using the same six-point Likert type scale ranging from 6 ("very definitely is a source") to 1 ("very definitely is not a source"). Example items of this scale include the following:

i) Informing patients about their health state

ii) Negative exposure in mass media

iii) Lack of cooperation by nursing staff

iv) The risk of infectious diseases

v) Cases where the patients are relatives or friends

vi) The sudden aggravation of patients' health

c) Job Satisfaction/Dissatisfaction Scale [49]. Job satisfaction was measured using a 15 -item scale, which measures different elements of intrinsic and extrinsic satisfaction/dissatisfaction $(\alpha=.79)$. It is a

Table 2 Mean scores, standard deviations and frequency of job

\begin{tabular}{lll}
\hline Sources of Job Dissatisfaction $^{a}$ & Mean \pm SD & N (\%) \\
\hline 1. Financial matters & $3.03 \pm 1.60$ & $216(42 \%)$ \\
2. Workload & $3.24 \pm 1.63$ & $186(36.2 \%)$ \\
3. Lack of promotion opportunities & $3.16 \pm 1.44$ & $185(36 \%)$ \\
4. Hospital working conditions & $3.53 \pm 1.58$ & $141(27.4 \%)$ \\
5. Relationships with the management & $3.64 \pm 1.56$ & $122(23.7 \%)$ \\
6. Job security & $3.97 \pm 1.73$ & $119(23.1 \%)$ \\
7. Feedback by the superiors & $4.54 \pm 1.61$ & $108(21 \%)$ \\
8. Freedom of working style & $3.77 \pm 1.49$ & $106(20.6 \%)$ \\
9. Job diversity & $4.14 \pm 1.58$ & $92(17.9 \%)$ \\
10. Accomplishment opportunities & $3.94 \pm 1.43$ & $86(16.7 \%)$ \\
11. Attention to the suggestions & $4.13 \pm 1.48$ & $82(16 \%)$ \\
12. Colleagues & $4.22 \pm 1.51$ & $69(13.4 \%)$ \\
13. Superiors & $4.54 \pm 1.61$ & $67(13 \%)$ \\
14. Working responsibilities & $4.47 \pm 1.46$ & $59(11.5 \%)$ \\
15. Appreciation for my good performance & $4.24 \pm 1.42$ & $55(10.7 \%)$ \\
\hline
\end{tabular}

Dissatisfaction sources. (Answer to the question: "From which organisational factors are you totally satisfied or totally dissatisfied")

${ }^{\text {a }}$ All 15 items of the questionnaire are included
Likert-type scale that ranges from $1=$ totally dissatisfied to $7=$ totally satisfied.

d) Personal and job demographics. Each participant supplied data on specialism, gender, age, marital status, number and age of children, years in present job, alcohol intake, social contact with colleagues, and, financial commitments. In addition, data was obtained with respect to existence and frequency of headaches. The latter question was included after the 60 interviews with Greek hospital doctors showed that headaches/migraines were reported as their most frequent physical symptom caused by stressful working conditions.

\section{Results}

Table 2 presents the sources of job dissatisfaction for hospital doctors, measured using the Job Satisfaction Scale [49], together with descriptive statistics. Financial issues achieved the lowest score, and were the most frequently reported source of dissatisfaction, being indicated by $42 \%$ of the sample. Doctors were also dissatisfied from the workload and the lack of promotion opportunities ( $m=3.24$ and $m=3.16$ respectively). Interestingly, a $1 / 4$ of the sample generally regarded the working conditions in the hospital as an important source of job dissatisfaction. On the other hand, higher levels of satisfaction were reported from relationships with superiors $(m=4.54)$ and colleagues $(m=4.22)$, work responsibilities $(m=4.47)$, and, finally the recognition they receive for their work $(m=4.24)$.

As demonstrated in Table 3, Factor Analysis on occupational stressors revealed eight factors. These factors cover the $52.5 \%$ of the total variance, have a high reliability level ranging from .69 to .87 and compose homogeneous groups. It is concluded that the factors have estimated properly since all variable loadings were particularly high (above .69) and all items have contributed to these emerging factors.

Taking the overall total job satisfaction score as a dependent variable, stepwise multiple regression was applied, in order to determine specific predictors of job

Table 3 Factor analysis for the occupational stressors

\begin{tabular}{lccc}
\hline Factor name & Eigen value & \% Variance & A \\
\hline 1. Specific working conditions & 21.7 & 30.2 & .87 \\
2. Social support & 3.2 & 4.5 & .84 \\
3. Hospital's environment & 2.7 & 3.8 & .87 \\
4. Heavy Duties & 2.3 & 3.3 & .84 \\
5. Patients' care & 2.1 & 3.0 & .85 \\
6. Training/medical information & 1.9 & 2.7 & .83 \\
7. Interpersonal relationships/conflicts & 1.8 & 2.5 & .74 \\
8. Communication with patients \& relatives & 1.8 & 2.5 & .69 \\
\hline
\end{tabular}


Table 4 Regression analysis with total job satisfaction as dependent variable

\begin{tabular}{llllll}
\hline Dependent variable & Independent variable & $\mathrm{R}^{2}$ & Beta & $\mathrm{T}$ & $\mathrm{P}$ \\
\hline Total Job satisfaction & Working conditions & .102 & -.227 & -5.73 & .000 \\
& Social support & .153 & -.095 & -2.41 & .016 \\
& Environment & .189 & -.190 & -4.81 & .000 \\
& Heavy duties & .199 & -.319 & -8.07 & .000 \\
& Patient care & .205 & .082 & 2.06 & .039 \\
& Presence of headaches & .043 & -.203 & -4.72 & .000 \\
& Specialism & .052 & .101 & 2.35 & .019 \\
& Age & .017 & .129 & 2.93 & .003 \\
\hline
\end{tabular}

satisfaction/dissatisfaction in Greek hospital doctors. The independent variables entered included the 8 factors of occupational stress (Table 3), together with the demographic variables outlined above. Stress factors in relation to working conditions, social support, environment, heavy duties and patient care were all found to be predictors of overall job satisfaction/dissatisfaction (see Table 4). Additionally, physical symptoms in the form of headaches were also identified with greater satisfaction being associated with less headaches $(r=-.21, p=<0.01)$. Predicting demographic factors included specialism, and age, with greater satisfaction associated with increased age $(r=.13, p=<0.01)$.
As salary, workload, promotion opportunities and working conditions were found to be the four conditions with which doctors expressed highest job dissatisfaction, stepwise regression was again applied, in order to identify specific predictors of dissatisfaction with these particular aspects of working life. The results showed that the most commonly occurring stressors affecting aspects of job dissatisfaction included working conditions, heavy duties, and the hospital environment (see Table 5). Thus, when doctors feel tension in regard to these three factors, they also manifest lower levels of job satisfaction. For dissatisfaction with workload, training and information was also identified as a predicting stressor. Presence of headaches was associated with all 4 aspects of job dissatisfaction, with higher levels of dissatisfaction leading to a greater incidence of headaches. Predicting demographic variables included specialism (surgeons reporting greater levels of dissatisfaction), gender (females indicate lower levels of dissatisfaction), and age (younger doctors demonstrate more dissatisfaction).

The effects of key stressors on aspects of working life attracting the highest levels of job satisfaction were also examined, the results of which are demonstrated in Table 6. Frequently occurring predicting stressors consisted of social aspects including social support, patients' care, communication and interpersonal relationships. Thus, it appears that these particular stressors enhance

Table 5 Regression Analyses with most prominent aspects of job dissatisfaction as dependent variables

\begin{tabular}{|c|c|c|c|c|c|}
\hline Dependent variable & Independent variable & $R^{2}$ & Beta & $\mathrm{T}$ & $P$ \\
\hline \multirow[t]{5}{*}{ Salary } & Working conditions & .060 & -.244 & -5.93 & .000 \\
\hline & Heavy duties & .104 & -.210 & -5.10 & .000 \\
\hline & Environment & .137 & -.183 & -4.45 & .000 \\
\hline & Presence of headaches & .024 & -.156 & -3.57 & .000 \\
\hline & Gender & .017 & .131 & 3.00 & .003 \\
\hline \multirow[t]{5}{*}{ Specific working conditions } & Heavy duties & .074 & -.272 & -6.58 & .000 \\
\hline & Environment & .109 & -.188 & -4.56 & .000 \\
\hline & Working conditions & .132 & -.151 & -3.66 & .000 \\
\hline & Presence of headaches & .037 & -.185 & -4.30 & .000 \\
\hline & Specialism & .062 & .161 & 3.74 & .000 \\
\hline \multirow[t]{3}{*}{ Promotion } & Heavy duties & .094 & -.306 & -7.49 & .000 \\
\hline & Environment & .149 & -.236 & -5.77 & .000 \\
\hline & Presence of headaches & .057 & -.240 & -5.58 & .000 \\
\hline \multirow[t]{8}{*}{ Workload } & Heavy duties & .192 & -.438 & -11.36 & .000 \\
\hline & Training/information & .215 & .154 & 3.99 & .000 \\
\hline & Working conditions & .236 & -.146 & -3.78 & .000 \\
\hline & Environment & .245 & -.094 & -2.44 & .015 \\
\hline & Presence of headaches & .067 & -.251 & -5.97 & .000 \\
\hline & Specialism & .099 & .179 & 4.25 & .000 \\
\hline & Gender & .028 & .113 & 2.57 & .010 \\
\hline & & .015 & .131 & 2.99 & .004 \\
\hline
\end{tabular}


Table 6 Regression analyses with most prominent aspects of job satisfaction as dependent variables

\begin{tabular}{|c|c|c|c|c|c|}
\hline Dependent variable & Independent variable & $R^{2}$ & Beta & $\mathrm{T}$ & $P$ \\
\hline \multirow[t]{3}{*}{ Relationships with colleagues } & Patients care & .062 & .250 & 5.87 & .000 \\
\hline & Heavy duties & .076 & -.116 & -2.72 & .007 \\
\hline & Socialising with colleagues & .012 & -.111 & -2.42 & .015 \\
\hline \multirow[t]{4}{*}{ Appreciation } & Social support & .039 & -.197 & -4.71 & .000 \\
\hline & Working conditions & .077 & -.195 & -4.65 & .000 \\
\hline & Heavy duties & .107 & -.175 & -4.17 & .000 \\
\hline & Age & .018 & .134 & 3.05 & .002 \\
\hline \multirow[t]{3}{*}{ Relationships with supervisors } & Social support & .038 & -.194 & -4.58 & .000 \\
\hline & Patients care & .069 & .175 & 4.14 & .000 \\
\hline & Working conditions & .085 & -.1130 & -3.07 & .002 \\
\hline \multirow[t]{6}{*}{ Work responsibilities } & Heavy duties & .022 & -.147 & -3.41 & .001 \\
\hline & Environment & .033 & -.107 & -2.47 & .014 \\
\hline & Communication with patients and relatives & .044 & -.102 & -2.37 & .018 \\
\hline & Interpersonnal relationships & .053 & -.099 & -2.30 & .022 \\
\hline & Age & .024 & .155 & 3.54 & .000 \\
\hline & Marital status & .032 & -.179 & -2.44 & .015 \\
\hline
\end{tabular}

Greek doctors satisfaction in terms of relationships with supervisors and colleagues, appreciation, and responsibilities. However, heavy duties, working conditions and hospital environment were also indicated, demonstrating that these three factors are associated with levels of job satisfaction, as well as with job dissatisfaction. Demographic variables affecting doctors satisfaction included socialising with colleagues, age and marital status, whereby: those who mix with their colleagues at a social level are more likely to report satisfaction in their relationships with them; increased age is associated with greater satisfaction in terms of appreciation $(r=.13, p=<0.01)$ and responsibilities $(r=.16, p=<0.01)$, and Greek doctors who are married are more likely to express satisfaction with their responsibilities $(f=2.41, P=.048)$.

\section{Discussion}

The findings of this study demonstrate that a number of key stressors have an impact on overall job satisfaction in Greek hospital doctors. In particular, working conditions, the hospital environment and heavy duties represent highly significant effects. With regard to physical and demographic variables as potential predictors of satisfaction, presence of headaches, specialism and age were significantly linked to the overall job satisfaction of the sample of Greek doctors investigated within this research.

In addition to total job satisfaction, key aspects of job dissatisfaction/job satisfaction were investigated in order to identify specific stressors contributing to these. According to the results of the study, and as expected, an important source of job dissatisfaction for Greek hospital doctors is related to salary levels. Financial matters in regard to the medical personnel have been the focus of attention for Greek social organizations and mass media for a long time [21]. Hospital doctors assert that their salaries are not in balance with their contribution toward society, especially when compared to other working groups with the same working experience and much higher salaries. In comprehensive interviews with the authors, doctors have argued that low salaries are strongly related to corruption incidents that often occur in the Greek hospital environment, and especially in specialties such as surgery. A previous survey amongst junior doctors working in Greek hospitals [4] has also revealed insufficient finances as a source of occupational stress.

As well as the identification of salaries as a key area of job dissatisfaction among Greek hospital doctors, dissatisfaction with respect to specific working conditions, promotion opportunities and workload were also identified. In most cases, as with the total score mentioned above, heavy duties, working conditions and the environment were significant predictors. Previous research by Falagas et al. [19] noted a number of common physical complaints amongst Greek doctors. In the current study, the presence of headaches was shown to be linked to dissatisfaction with salaries, working conditions, promotion and workload.

With regard to the predictability of demographic variables, few of these were found to effect job dissatisfaction. However, gender had a significant effect on salaries and workload, with female doctors expressing less 
dissatisfaction, whilst specialism was a predicting factor with respect to workload and specific working conditions.

When key aspects of job satisfaction were investigated, relationships with colleagues and supervisors, appreciation and responsibilities emerged as the occupational factors with which Greek doctors were most satisfied. In most cases, predictors of such satisfaction were connected to social aspects including social support, patient care, communication and interpersonal relationships. Thus, the less stress encountered in these areas, the more satisfied Greek doctors are with the factors outlined above. Furthermore, reduced stress with regard to heavy duties, working conditions and environment appears to be associated with increased satisfaction. Examination of demographic variables revealed that socialising with colleagues, age, and marital status were also predicting factors with regard to job satisfaction, with older doctors and those who are married, expressing greater satisfaction.

The results from this study have identified a number of significant predictors of both job dissatisfaction and job satisfaction in Greek hospital doctors. Regarding the sources of occupational stress in Greek hospital doctors, the 'specific working conditions' factor strongly correlates to the occupational pressure experienced, and the subsequent job dissatisfaction. This is understandable, since this factor refers to the need for extra space in hospitals, the lack of necessary expendable supplies, lack of hospital equipment and the decreased collaboration between specialties and departments. This finding supports our hypotheses that the structure of the Greek NHS, and related problems concerning resources and administration are probable stress factors leading to dissatisfaction in Greek hospital doctors. Various international studies (e.g., [7, 17]) are consistent with the above results, indicating that deficient hospital working conditions, or the lack of hospital equipment which could facilitate the medical practice, are strongly correlated to high levels of job dissatisfaction, as well as to limited opportunities of interpersonal communication.

Hospital doctors, and especially Junior Doctors, who spend a considerable part of their time in hospital environments, have to confront a number of adversities that can often result in high levels of strains. Such adversities may affect patients' care, which in turn might be an additional source of stress for the doctors [20, 32]. Moreover, lack of sufficient nursing personnel in Greek hospitals may also affect the doctors' role, leading to greater levels of disorganisation and ineffectiveness. As such, the ambiguity in the nature of the doctors' job role often requires them to conduct nursing duties, or hospital 'porter' responsibilities [35].

'Heavy duties' (Factor 4) was also revealed as an important stressor, predicting Greek Doctors' job satisfaction.
This finding is in accordance with the literature, which suggests that workload for hospital doctors and the subsequent time pressures, and constraints are crucial stress sources for medical personnel (e.g., [18]). Research suggests that partnership and practice arrangements help doctors to manage their workload better [27], but it appears that in Greek Hospitals, co-ordination with other medical personnel within the hospital (including nursing staff) is scarce.

It has become clear that the structure of the Greek National Health System and difficulties in the co-ordination of medical personnel are significant sources of stress for the public hospital doctors. Thus, it is reasonable to expect that under these circumstances, doctors will feel frustrated and distressed, with possible consequences regarding their mental health and their performance [44]. The relevant context specificity of potential stressors should however be highlighted; salary levels and insufficient finance appear to be an important issue for Greek hospital doctors; their wages have been frozen for over a decade, an issue which dis-allows doctors to cover the expenses of their professional development [4]. Such factors should be interpreted in the light of the realities within the Greek health system.

With regard to job satisfaction however, it seems that a number of 'social' factors may help to contribute to greater satisfaction in Greek hospital doctors. This is also in accordance with our hypothesis, given the traditional societal values and social construct of Greece, predominantly rooted in the family as a central cultural institution [22]. Thus, the findings might imply that the enhancement of support systems, and focus on improving interpersonal relationships and communication could have positive psychological effects on the wellbeing and job satisfaction of hospital doctors in Greece.

The current study is not without limitations. The use of a correlational design does not permit any cause and effect inferences between the dependent and independent variables. Only a longitudinal study could establish with greater certainty a causal relationship between occupational stressors and subsequent job dissatisfaction/ satisfaction. An additional limitation of the current study is it's exclusive reliance upon self-administered questionnaires creating two problems; first, as it was clear that stress was the focus of this research, reported stress levels may be inflated due to bias in who responds (stressed doctors might be more likely to respond) and how they respond (probability to exaggerate in stress responses when stress is the topic of research) [30].

Despite the study limitations, the findings represent clear implications for policy and practice. The focus of organisational change should be primarily on prevention but also on correctional steps, for example, rates of pay should be improved, an adequate number of staff available to cover the workload should be assured, improved practice 
management, encouragement of partnerships, improved communication and co-ordination with other medical personnel within the hospital (including nurses), should be addressed. Continuing medical education and perceived opportunities for keeping up-to-date with the medical and professional developments may also reduce occupational stress and dissatisfaction, and thus improve satisfaction [29]. Risk assessment and risk management for workrelated stress should be implemented as a useful tool that can identify major stressors within hospitals and assist government and policymakers to reduce these [14]. These issues are of particular importance, since stress and dissatisfaction have a direct impact on quality of patients' care and treatment, and on doctors' psychological and physical health

However, on the basis that policies with regard to significant changes in Greek doctors salaries and resources may not be forthcoming in the immediate future, identification of key areas of satisfaction and predictors of these may also lead to important initiatives aimed at increasing social support, boosting morale and improving well-being. The findings of this study may also have wider implications, given the regional structure of Greece, and possible similarities with neighbouring countries.

\section{Conclusions}

The results of this study identify that certain stress factors influence the overall job satisfaction of Greek hospital doctors. Specifically, adverse working conditions, the hospital environment and heavy duties represent highly remarkable effects. For example, lack of sufficient nursing personnel in Greek hospitals may also affect the doctors' role, leading to greater levels of disorganisation and ineffectiveness. In general, hospital doctors showed significantly lower levels of job satisfaction concerning their salary, working hours, opportunities for promotion and working conditions. On the other hand, the highest levels of job satisfaction were indicated with regard to relationships with colleagues and superiors, responsibilities, and appreciation for their work. Finally, as regards to physical and demographic variables as potential predictors of job satisfaction, presence of physical symptoms, specialism and age were significantly associated to the overall job satisfaction of the sample of Greek doctors investigated within this research.

\section{Competing interests}

The authors declare that they have no competing interests.

\section{Authors' contributions}

ASA, CLC and MJD developed study idea. ASA conducted the study and drafted the manuscript. CLC and MJD contributed to improving the manuscript. All authors read and approved the final manuscript.

\section{Author details}

${ }^{1}$ National and Kapodistrian, University of Athens, Athens, Greece. ${ }^{2}$ University of Manchester, Manchester, UK.
Received: 5 January 2016 Accepted: 10 March 2016

Published online: 25 March 2016

\section{References}

1. Antoniou AS, Cooper CL, Davidson MJ. Occupational stress and coping strategies of junior doctors: presentation of the quantitative data. London: Presentation to Annual Conference of British Psychological Society; 2000.

2. Antoniou AS. Occupational stress: acute and chronic stress factors, Eleftherotypia, 100, special issue on "Occupational stress: the secret enemy". 2001.

3. Antoniou AS. Sources of occupational stress-european week for safety and health at work. Athens: Ministry of Work and Employment and Hellenic Institute of Hygiene and Safety Work; 2002.

4. Antoniou AS, Davidson MJ, Cooper CL. Occupational stressors, job satisfaction and health state in male and female junior hospital doctors in Greece. J Manag Psychol. 2003;18:592-621.

5. Arnetz BB, Andreasson S, Strandberg M, Eneroth P, Kallner A. Comparison between surgeons and general practitioners with respect to cardiovascular and psychosocial risk factors among physicians. J Work Environ Psychol. 1988;14:118-24.

6. Athanassopoulos A, Gounaris C. Assessing the technical and allocative efficiency of hospital operations in Greece and its resource allocation implications. Eur J Oper Res. 2001;133:416-31.

7. British Medical Association. Stress and the medical profession. London: BMA; 1992.

8. Burbeck R, Coomber S, Robinson SM, Todd C. Occupational stress in consultants in accident and emergency medicine; a national survey of levels of stress at work. Emerg Med. 2002;19:234-8.

9. Caplan RP. Stress, anxiety and depression in hospital consultants, general practitioners and senior health service managers. Br Med J. 1994;309:1261-3.

10. Coomber S, Todd C, Park G, Baxter P, Firth-Cozens J, Shore S. Stress in UK intensive care unit doctors. Br J Anaesth. 2002;89:873-81.

11. Cooper CL, Rout U, Faragher B. Mental health, job satisfaction and job stress in general practitioners. Br Med J. 1989;298:366-70.

12. Cooper CL, Sloan SL, Williams SL. Occupational stress indicator management guide. Windsor: NFER-NELSON; 1988.

13. Cooper $\mathrm{CL}$, Williams J. A validation study of the OSI on a blue-collar sample. Stress Med. 1991;7:109-12.

14. Cox T, Griffiths A, Macafee M, Rial-Gonzalez E. The assessment and management of work-related stress in doctor, Final report to the British medical association board of science and education. 1998.

15. Davaki K, Mossialos E. Plusça change: health sector reforms in Greece. J Health Polit Policy Law. 2005;30:143-68.

16. Davis HA. A re-analysis of the occupational stress indicator. Work Stress. 1990;10:174-82.

17. Dudley HA. Stress in junior doctors. 1-Stress and support. Br Med J. 1990; 301:75-6.

18. Enzer I, Sibbald B. General Practitioners' work satisfaction in 1998, executive summary 13. University of Manchester: NPCRDC; 1999.

19. Falagas ME, Bliziotis IA, Soteriades ES. A prospective study of services utilization of a hospital-based employee health clinic. Med Sci Monit. 2006; 12:341-4

20. Firth-Cozens J. Stress, psychological problems, and clinical performance. In: Vincent C, Ennis M, Audley RJ, editors. Medical accidents. Oxford: Oxford University Press; 1993.

21. Foura G. The new salaries' levels of hospital doctors, The Daily [I Kathimerini]. 1997. Sunday 7 September, 23.

22. Georgas J, Berry JW, Shaw A, Christakopoulou S, Mylonas K. Acculturation of Greek family values. J Cross-Cult Psychol. 1996;27:329-38.

23. Grainger $C_{\text {, Harries }}$, Temple J, Griffiths R. Job satisfaction and health of house officers in the West Mindlands. Health Trends. 1995;27:27-30.

24. Griffiths J. Handbook for the hospital medical secretary. London: Blackwell Scientific Publications; 1993.

25. Grol R, De Maesenner J, Whitfield M, Mokkink H. Disease-centred versus patient-centred attitudes: comparison of general practitioners in Belgium, Britain and The Netherlands. Fam Pract. 1990;7:100-3.

26. Grol R, Mokkink H, Smits A, Van Ejik J, Beek M, Mesker P, et al. Work satisfaction of general practitioners and the quality of patient care. Fam Pract. 1985;2:128-35.

27. Huby G, Gerry M, McKinstry B, Porter M, Shaw J, Wrate R. Morale among general practitioners: qualitative study exploring relations between partnership arrangements, personal style, and workload. Br Med J. 2002;325:140-4. 
28. King MB, Cockcroft A, Gooch C. Emotional distress: sources, effects and help sought. J R Soc Med. 1992;85:605-8.

29. Kushnir T, Cohen AH, Kitai E. Continuing medical education and primary physicians' job stress, burnout and dissatisfaction. Med Educ. 2000;34:430-6.

30. McManus IC, Winder BC, Gordon D. Are UK doctors particularly stressed? Lancet. 1999;354:1358-9.

31. Mossialos E, Allin S, Davaki K. Analysing the Greek health system: a tale of fragmentation and inertia. Health Econ. 2005;14:151-68.

32. Moss F. Junior doctors: waving or drowning? Br Med J. 1999;318:1639-40.

33. Myerson S. Doctors' methods of dealing with "on going" stress in general practice. Med Sci Res. 1991;19:267-9.

34. Pappa E, Niakas D. Assessment of health care needs and utilization in a mixed public-private system: the case of the Athens area. BMC Health Sery Res. 2006;6:146.

35. Pipili L. The lost "honour" of Greek doctors, The Sunday Pace [To Vima tis Kyriakis]. 1996. p. 84-5.

36. Polyzos A, Gennatas C, Veslemes M, Daskalopoulou E, Stamatiadis D, Katsilambros $\mathrm{N}$. The smoking-cessation promotion practices of physican smokers in Greece. J Cancer Educ. 1995;10:78-81.

37. Porter A, Howie J, Levinson A. Stress and the general practitioner. In: Payne R, Firth-Cozens J, editors. Stress in health professionals. Chichester: Wiley; 1987. p. 45-70.

38. Ramirez AJ, Graham J, Richards MA, Cull A, Gregory WM. Mental health of hospital consultants; the effects of stress and satisfaction at work. Lancet. 1996;347:724-8.

39. Richardsen AM, Burke RJ. Occupational stress and work satisfaction among Canadian women and physicians. Psychol Rep. 1993;72:811-21.

40. Riley GJ. Understanding the stresses and strains of being a doctor. Med J Aust. 2004;181:350-3.

41. Rout U, Cooper CL, Rout JK. Job stress among British general practitioners: Predictors of job dissatisfaction and mental ill-health. Stress Med. 1998;12:144-66.

42. Rovithis D. Health economic evaluation in Greece. Int J Technol Assess Health Care. 2006:22:388-95.

43. Schattner PL, Coman GJ. The stress of metropolitan general practice. Med J Aust. 1998:169:133-7.

44. Sutherland VJ, Cooper CL. Job stress, satisfaction and mental health among general practitioners before and after the introduction of the new contract. Br Med J. 1992;304:1545-8.

45. Sutherland VJ, Cooper CL. Identifying distress among general practitioners: predictors of psychological ill health and job dissatisfaction. Soc Sci Med. 1993;37:575-81.

46. Theorell T, Ahlberg-Hullten G, Sigala F, Perski A, Soderholm M, Kallner A, et al. A psychosocial and biomedical comparison between men in six contracting service occupations. Work Stress. 1990;45:51-63.

47. Tountas Y. Reforming the reform: the Greek national health system in transition. Health Policy. 2002:62:15.

48. Tselebis A, Papaleftheris E, Balis E, Theotoka I, Ilias I. Smoking related to anxiety and depression in Greek medical staff. Psychol Rep. 2003:92:529-32.

49. Warr PB, Cook J, Wall TD. Scales for the measurement of some work attitudes and aspects of psychological well being. J Occup Psychol. 1979;52:129-48

\section{Submit your next manuscript to BioMed Central and we will help you at every step:}

- We accept pre-submission inquiries

- Our selector tool helps you to find the most relevant journal

- We provide round the clock customer support

- Convenient online submission

- Thorough peer review

- Inclusion in PubMed and all major indexing services

- Maximum visibility for your research

Submit your manuscript at www.biomedcentral.com/submit

) Biomed Central 